\title{
INFÂNCIA LÍQUIDA, CRIANÇAS TRADUZIDAS, IDENTIDADES HÍBRIDAS: REFLEXÕES SOBRE A EDUCAÇÃO FÍSICA NA EDUCAÇÃO DE CRIANÇAS
}

Victor José Machado de Oliveira, Universidade Federal do Espírito Santo - UFES, Espírito Santo - Brasil

\section{RESUMO}

Este ensaio é fruto das discussões iniciadas na disciplina Educação Física e Cotidiano Escolar do PPGEF/CEFD/UFES. Foi realizada uma reflexão aprofundada sobre os conceitos de identidade, cultura, cotidiano e consumo com o objetivo de refletir sobre as relações entre a construção das identidades de infância no/com o cotidiano e suas possibilidades de pensar a educação física na educação de crianças. Constatou-se que as identidades de infância produzidas (traduzidas) são híbridas. Isso indica algumas possibilidades: conceber a infância na condição de possibilidades de tradução via inserção dessa na/à cultura corporal mediante a potencialização do consumo produtivo.

Palavras-Chave: Cotidiano; Identidade de infância; Identidades híbridas; Prática pedagógica; Infância líquida.

\section{LIQUID CHILDHOOD, CHILDREN TRANSLATED, HYBRID IDENTITIES: REFLECTIONS ON PHYSICAL EDUCATION IN THE EDUCATION OF CHILDREN}

\begin{abstract}
This essay is the result of discussions initiated in discipline Physical Education and Everyday School of PPGEF/CEFD/UFES. Thorough discussion was performed on the concepts of identity, culture, everyday and consumption with the aim to reflect on the relationships between the construction of identities of childhood in/with everyday and its possibilities of thinking about physical education in education of children. It found that the identities of childhood produced (translated) are hybrid. This indicates some possibilities: conceive childhood in the condition of possibility of translation via insertion of this in/on corporal culture through the potentiating of productive consumption.
\end{abstract}

Key-Words: Daily life; Identity childhood; Hybrid identities; Teaching practice. 


\section{NET NIÑES, NIÑOS TRADUCIDOS, IDENTIDADES HÍBRIDAS: REFLEXIONES SOBRE LA EDUCACIÓN FÍSICA EN LA EDUCACIÓN DE LOS NIÑOS \\ RESUMEN}

Este ensayo es el resultado de los debates iniciados en la disciplina Educación Física y Cotidiano Escolar del PPGEF/CEFD/UFES. Discusión a fondo se llevó a cabo en los conceptos de identidad, cultura, cotidiano y el consumo a fin de reflexionar sobre la relación entre la construcción de las identidades de la infancia en/con el cotidiano y de sus posibilidades de pensar acerca de la educación física en la educación de los niños. Se constató que las identidades de la infancia producidas (traducidas) son híbridas. Esto indica algunas posibilidades: pensar la infancia como posibilidades de traducción vía la inserción de esta en/sobre la cultura corporal a través de la potenciación del consumo productivo.

Palabras-Clave: Cotidiano; Identidad de infancia; Identidades híbridas; Práctica pedagógica. 


\section{INTRODUÇÃO}

Estudos sociológicos têm indicado que a cultura moderna vem sofrendo mudanças na sua forma. Nesse espectro, as relações sociais e os modos de viver contemporâneos já não são os mesmos que os de nossos pais e avós. Essa nova forma de vida parece incidir decisivamente nas relações estabelecidas na educação das crianças pequenas e em suas culturas de vida. Cabe então perguntar nesse momento sobre o papel ou o local que a educação física tem assumido nesse cenário contemporâneo, especificamente, na educação infantil.

A infância tem sido ultimamente lócus de atenção sendo desenvolvida nesta temática uma variação de pesquisas e estudos - na Educação Física e outras áreas - em diversas perspectivas teóricas e metodológicas. ${ }^{1-5}$ Nossa opção pelo tema foi fomentada durante o curso na disciplina Educação Física e Cotidiano Escolar do Programa de Pós-Graduação em Educação Física da Universidade Federal do Espírito Santo.

Inicialmente percebe-se que a infância foi dispersa na modernidade e destituída de identidade própria. A conformação da identidade infantil, e de sua institucionalização, acompanha os solavancos da constituição da modernidade e de suas transformações, em especial sua crise e transição de um estado sólido para um líquido, ${ }^{6-7}$ quando esta é reinstitucionalizada $^{1}$. Nesse sentido, a modernidade líquida configura infâncias líquidas. ${ }^{8}$ São nesses termos que surge uma cultura infantil, lócus privilegiado da identificação infantil, influenciado ainda pelo determinismo adultocêntrico e colonizador, mas com protagonismos das crianças que passam a "assumir poderes não existentes na história da humanidade até então". 8:202 Na modernidade em sua fase líquida ${ }^{6-7}$ ampliar a visão sobre a cultura infantil para uma cultura traduzida implica tomar a infância enquanto um exemplo, segundo Hall, ${ }^{9}$ de cultura híbrida. Cabe salientar que o autor não escreve sobre infância, entretanto, suas considerações acerca da identidade cultural na "pós-modernidade" têm contribuído para as reflexões realizadas nesse texto.

É imprescindível delimitar qual nossa visão de identidade, já que este conceito será o eixo aglutinador das discussões. Segundo nos informa Hall, ${ }^{9}$ a identidade não é algo acabado, Conexões: revista da Faculdade de Educação Física da UNICAMP, Campinas, v. 12, n. 3, p. 121-140, jul./set. 2014. ISSN: 1983-9030 
pelo contrário, deveríamos falar de "identificação" no tom de um processo em andamento. A identidade mostra-se como uma ambivalência, ${ }^{6}$ pois ao mesmo tempo em que está dentro de nós nos causa "uma falta" de inteireza que é preenchida em nossas relações com o outro - exterior. ${ }^{9}$

Diferentemente de outras correntes que abarcaram na modernidade em seu estágio sólido ${ }^{6}$ o conceito de identidade aqui expressado “[...] perde um sentido estável e ganha uma dimensão dinâmica e plural". ${ }^{10: 2}$ Reconhecemos essa colocação como um processo empregado na nova conformação social que emerge na modernidade líquida, ${ }^{6-7}$ que indica uma flexibilização dos contornos sociais - fruto das ambivalências produzidas no seio do projeto moderno de ordenação do mundo.

Nesse sentido, este ensaio foi dividido em três momentos onde tentamos operar com os conceitos de identidade, cultura, ${ }^{9}$ cotidiano $^{11}$ e consumo. ${ }^{12}$ Inicialmente, focamos a discussão entre Tradição/Tradução e como esses conceitos contribuem para o entendimento da construção das identidades de infância. Em seguida, caracterizamos o diálogo enviesado no/com o cotidiano no jogo da construção de identidades híbridas. Desse ponto, passamos a discutir a questão da tradução de crianças sobre o enfoque do consumo e suas (implic)ações para a Educação Física.

Elegemos como objetivo de trabalho discutir quais as relações da construção das identidades de infância (líquida) emerge no/com o cotidiano e suas possibilidades de pensar a Educação Física na educação de crianças.

\section{TRADIÇÃO E TRADUÇÃO: IMPLICAÇÕES PARA A CONSTRUÇÃO DAS IDENTIDADES DE INFÂNCIA}

Inicialmente consideremos o conceito de Tradução: a etimologia da palavra vem do latim e significa "transferir", "transportar entre fronteiras". A esse modelo surge a figura do migrante: sujeito pertencente a mais de dois mundos, que ao mesmo tempo transportado através desses, é um sujeito traduzido ${ }^{9}$. Ora, só há tradução de algo que esteja posto anteriormente. Emerge então o conceito de Tradição.

Conexões: revista da Faculdade de Educação Física da UNICAMP, Campinas, v. 12, n. 3, p. 121-140, jul./set. 2014. ISSN: 1983-9030 
A Tradição pode ser relacionada à formação da identidade nacional. Entretanto a questão central indica que essas identidades não são realmente unificadas. "Uma cultura nacional nunca foi um simples ponto de lealdade, união e identificação simbólica. Ela também é uma estrutura de poder cultural".9:59 Nesse sentido, Hall ${ }^{9: 88}$ classifica tradução:

Este conceito descreve aquelas formações de identidade que atravessam e intersectam as fronteiras naturais, compostas por pessoas que foram dispersadas para sempre de sua terra natal. Essas pessoas retêm fortes vínculos com seus lugares de origem e suas tradições, mas sem a ilusão de um retorno ao passado. Elas são obrigadas a negociar com as novas culturas em que vivem, sem simplesmente serem assimiladas por elas e sem perder completamente suas identidades.

Em analogia com a infância, percebe-se que a criança possui fortes vínculos com a família (seu lugar de origem), entretanto, ela é dispersa - pela cultura ocidental, criada historicamente para ela - para outros locais como, por exemplo, a escola, a rua, as instituições modernas (assim como ela). Dessa forma, elas são obrigadas a negociarem, sempre, com as novas culturas em que passam a viver; a esse processo alguns autores têm chamado de aculturação e outros de socialização.

O que devemos compreender é que, nesse processo, as negociações permeiam relações de subversão ainda não delineadas. Nesse sentido, fica um questionamento: se a criança não perde sua identidade, mas assimila nas novas culturas traços para ela, então a que identidade infantil está se discursando? Ao ponderar formas de delimitar essa questão utilizaremos a expressão "identidade de infância".

Optamos por essa expressão - e não, por exemplo, a expressão de "identidade infantil" por julgarmos que ela possa delimitar uma compreensão menos "infantilizadora" da infância, que já carrega em sua etimologia as parcelas de seu "pecado": o termo infans significa aquela que é incapaz, que não tem condições, autonomia, etc. Uma identidade "de" infância denota uma identidade "de" alguém e não uma identidade meramente adjetivada a alguém - infantil (incapaz). Nesses termos, caminha uma visão de infância que remete a sua possibilidade de produzir, de uma condição poética. ${ }^{5}$

Durante o que se pensou na Idade Média de uma infância angelical, ou na Modernidade sólida de uma infância centrada numa única cultura infantil, ambas apontavam recorrências Conexões: revista da Faculdade de Educação Física da UNICAMP, Campinas, v. 12, n. 3, p. 121-140, jul./set. 2014. 
às aspirações de uma "pureza cultural". Entretanto, devido a condição hodierna da geração de infância tem nos permitido discutir tal postulação. Hall, ${ }^{9}$ ao discutir a questão da identidade cultural, nos fornece ferramentas para tecer considerações acerca de uma identidade de infância. Conforme o autor, as identidades são o produto das várias histórias e culturas interconectadas, ou seja, uma hibridização daqueles que são obrigados a abandonar a utopia de qualquer absolutismo étnico. Em conexão com nossos argumentos sobre as crianças, nos utilizamos das palavras de Hall: "elas são irrevogavelmente traduzidas". 9:89

Aproximando-nos do nosso contexto, concebemos que as crianças não são receptáculos vazios a priori, que ao serem cheios se conformam em uma pureza cultural. A constituição de suas identidades é atravessada, a todo o momento, pelos contextos (cada vez mais globalizados) em que vivem e partilham no cotidiano. Rompemos, nesse momento, com uma visão estritamente socializadora da infância para com ela compreendermos as interfaces culturais que promovem sua hibridização.

$\mathrm{Na}$ esteira de $\mathrm{Hall}^{9}{ }^{9}$ percebemos semelhanças quanto ao processo das migrações póscoloniais daqueles que deveriam aprender a habitar no mínimo duas identidades, falar duas linguagens culturais e negociar entre elas. Trata-se das novas diásporas onde "há muitos outros exemplos a serem descobertos". 9:89 Compreendemos que essas novas diásporas dialogam com a característica da infância como um entre-lugar - marcado pela heterogeneidade dos contatos estabelecidos com várias realidades diferentes - numa sociedade que vive transformações significativas nas estruturas de seu cotidiano. As culturas da infância se tornam, no processo de sua reinstitucionalização na contemporaneidade, objeto de pluralização e de diferenciação. ${ }^{1}$

O esforço realizado aqui é da tentativa de compreender a infância enquanto um desses exemplos aludidos por Hall. ${ }^{9}$ Nesse sentido, lançamos mão do paradigma indiciário ${ }^{13}$ como ferramenta, amplamente operante, para os estudos no/com o cotidiano. Pois, nos possibilita decifrar ou ler as pistas de uma temporalidade da infância - em específico da geração hodierna. Assim, podemos ler como dentre as linhas de um tapete o tecer de uma 
identidade de infância singular que, ao afastar de possíveis caricaturarizações, nos aproxima de novas perspectivas de análise dessa geração.

Os estudos no/com o cotidiano nos possibilita uma empreitada "chão a fundo" de forma que nos acheguemos à percepção da cultura ordinária: as operações dos praticantes que disputam, golpe a golpe, espaços no campo do inimigo. ${ }^{11} \mathrm{~A}$ partir da esteira de Certeau, ${ }^{11}$ podemos considerar que a identidade é parte integrante de uma estratégia gerada a partir dos dispositivos centrais do poder. Extrapolando esse argumento para a infância, compreendemos que essa estratégia é adultocêntrica, a qual procura traçar uma memória (infantil) a ser guiada e perpetuada. Mas ao mesmo tempo ela é atravessada pelas táticas de infância que operam mil formas de fazer com uma memória de lembranças e esquecimentos. Entendemos por táticas de infância os consumos produtivos ${ }^{11}$ que as crianças operam no cotidiano ao se relacionarem com os dispositivos dispostos pelos adultos - um certo (re)iventar novas formas de se fazer e estabelecer vínculos, sentidos e significados.

A grande relação desse pensamento consiste que os "senhores da memória" (o homem branco, adulto e europeu) direcionaram uma memória infantil daquilo que se perspectivava/perspectivou a infância. Esta é uma memória moderna, ocidental, racionalista e, se olharmos atentamente, perceber-se-á sua opacidade. Entretanto, "se a realidade é opaca, existem zonas privilegiadas - sinais e indícios - que permitem decifrála". 13:177 Concebemos que no cotidiano podemos obter uma zona privilegiada ao observar as ações das crianças em sua materialidade, buscando detetivescamente sinais e indícios de uma identidade de infância através da análise dos discursos, pinturas e escritas ${ }^{13}$ (e por que não do movimento?!).

Se nos é confiável a memória, lembremo-nos de um lema motivador da construção da identidade nacional: "as crianças são o futuro da nação". Elas são o futuro, mas também o presente. Nas palavras de Sarmento, ${ }^{1}$ são um entre-lugar, o espaço intersticial entre dois modos, dois tempos, que socialmente construído é renovado pela ação coletiva dessas. Ou seja, a criança é o aqui-agora, porque ela se doa as possibilidades do presente sem temer o futuro; mas, também ela é o próprio futuro daquilo que projeta em suas relações.

Conexões: revista da Faculdade de Educação Física da UNICAMP, Campinas, v. 12, n. 3, p. 121-140, jul./set. 2014. ISSN: 1983-9030 
Nessa esteira, a discussão irá à procura dos indícios que permitam decifrar essa geração como uma infância de identidades híbridas. Com relação a isso, concordamos que forte influência desse processo ocorre nos cotidianos liquefeitos cada vez mais globalizados. Processos que Santos ${ }^{14-15}$ tem chamado de cultura de fronteira.

\title{
O JOGO DAS IDENTIDADES NO/COM O COTIDIANO: IDENTIDADES HÍBRIDAS?
}

Cada sociedade observa a necessidade de distinguir os seus componentes; mas os modos de enfrentar essa necessidade variam conforme os tempos e os lugares. Existe antes de mais nada, o nome; mas, quanto mais a sociedade é complexa, tanto mais o nome parece insuficiente para circunscrever inequivocamente a identidade do indivíduo. ${ }^{13: 171-172}$

A infância é construída na modernidade sob a perspectiva do "sujeito sociológico".9

\begin{abstract}
A noção de sujeito sociológico refletia a crescente complexidade do mundo moderno e a consciência de que este núcleo interior do sujeito não era autônomo e auto-suficiente (sic.), mas era formado na relação com 'outras pessoas importantes para ele', que mediavam para o sujeito os valores, sentidos e símbolos - a cultura - dos mundos que ele/ela habitava. $9: 11$
\end{abstract}

Apesar de a figura do sujeito sociológico conferir centralidade na interação do sujeito com a sociedade, compreendemos que, em relação à criança, essa interação ocorreu de forma verticalizada, o que indica uma visão de sua "inferioridade" em relação as suas capacidades de participar nas interações que produzem cultura.

A partir dessas considerações, nos perguntamos: como, na contemporaneidade, a infância tem sido discursada? Qual relação (perspectivas) que a Sociologia da Infância apresenta sobre a infância? Quais os limites e possibilidades de pensar a infância através de novas abordagens teóricas enviesadas no discurso cultural? Que implicações isso trás nos estudos com o cotidiano?

Os estudos da Sociologia da Infância têm indicado uma concepção mais "aberta" da/na construção social da infância (só de se considerar que uma parcela - antes insignificativa seja tomada por interesse de estudo já indicam uma abertura teórico-metodológica além das perspectivas tradicionais e puramente estruturalistas). Assim, confere esta como uma Conexões: revista da Faculdade de Educação Física da UNICAMP, Campinas, v. 12, n. 3, p. 121-140, jul./set. 2014. ISSN: 1983-9030 
categoria social do tipo geracional que se juga relevante para a análise dos processos de relações sociais e da própria estratificação social. ${ }^{2}$ Compreendemos que a demarcação da infância a partir dessa perspectiva indica indícios de que existem facetas entreabertas para uma análise pelo viés cultural.

Em meio à problemática exposta, emerge a seguinte consideração: a criança é socializada em um meio específico, porém, em sua condição geracional ela assume características culturais e históricas específicas de sua temporalidade para a constituição de sua identidade. A questão posta está em perceber que a socialização não pode ser tangida aqui em um molde coercitivo a priori da conformação de identidades infantis de massa. Vale notar o processo de deslocamento apontado por Hall $^{9}$ como pano de fundo que localiza as identidades em transição no contexto de uma modernidade líquida. ${ }^{7}$ Nesse sentido, Jesus ${ }^{10}$ nos alerta que, no contexto globalizado, os mundos culturais estão em contínua transformação, assumindo concepções deslocadas.

A caminho dessa discussão encontramos em Bauman $^{6-7}$ ferramentas importantes para compreendermos a questão da hibridização das identidades na modernidade líquida inclusive nos termos de sua tessitura na discussão da ambivalência e das celeumas provocadas por essa na contemporaneidade. A ambivalência passa a ser um termo chave para a compreensão do deslocamento identificado por Hall $^{9}$ e para a constituição das identidades de infância, aqui tomadas heuristicamente, como identidades híbridas.

Por exemplo, em algum momento de nossas vidas já visualizamos algumas crianças brincando de casinha. O "brincar de casinha" destaca a ambivalência entre passado e futuro assim construindo, na relação "passado-presente-futuro", uma temporalidade. A relação com o passado se dá mediante a renovação de uma cultura infantil, que embora programada pelos adultos, é apropriada pelas crianças de diversas formas. Com relação ao futuro, concentra a noção de que esse repertório busca idealizar uma suposição de um vir a ser (devir). Quanto ao presente, podemos observar uma relação de um possível "não ser" nem o passado expressado adultocentricamente e nem o futuro que ainda não chegou. A

Conexões: revista da Faculdade de Educação Física da UNICAMP, Campinas, v. 12, n. 3, p. 121-140, jul./set. 2014. ISSN: 1983-9030 
criança joga o jogo das identidades, assim, construindo a sua própria, nas relações geracionais e interpessoais.

O jogo das identidades das crianças nasce no cotidiano, nas mil formas de fazer com usos e apropriações de uma cultura de infância que ao mesmo tempo construída exteriormente é reconstruída pelo consumo produtivo ${ }^{11}$ que essas operam. A condição presente dessas crianças de um "não ser" implica em reverberações exaustivas que não serão esgotadas aqui neste espaço (esclarecemos que não estamos indicando uma ausência ou incompetência do ser criança, mas, uma condição ambivalente que demarcou nossa percepção durante essas reflexões). É necessário direcionar um olhar na superfície das relações introduzidas nos espaços da educação infantil perscrutando a condição de infância que marca, em seu nome, cada vez menos uma identidade sólida e intangível no compasso da complexidade que emerge no contexto sociocultural (ou cultural-social). Compete uma operação metodológica que percorra o (des)conhecido atrás de indícios que delineiem uma proposta do que seria o vislumbre do real. Para tanto, indica Filarete apud Ginzburg, ${ }^{13: 163}$ "se olhares direito verás que há diferenças nas semelhanças".

Cabe ressaltar, novamente, que a cultura não é infantil a priori, ela é adjetivada de "infantil" dada às construções sociais designadas para aquele conjunto de representações e práticas. Isso já indica algumas "diferenças nas semelhanças" que possam surgir no cotidiano especificando os fluxos culturais que identificam as crianças de um dado contexto. Por exemplo, algumas crianças vivem o fenômeno do transporte escolar. Se observarmos a condição infantil (da dependência do transporte) é a mesma, mas a cultura de infância não: os meios para o transporte são diferenciados de outros contextos e até mesmo de outras gerações. E isso é só um (dos) exemplo(s).

Os fluxos culturais, entre as nações, e o consumismo global criam possibilidades de 'identidades partilhadas' - como 'consumidores' para os mesmos bens, 'clientes' para os mesmos serviços, 'públicos' para as mesmas mensagens e imagens - entre pessoas que estão bastante distantes umas das outras no espaço e no tempo.:74

As mesmas crianças que, num espaço-tempo do globo, utilizam as "topics" em seu transporte escolar, também partilham com crianças de outras partes uma cultura de consumo, um mercado de produtos para crianças, ${ }^{1}$ que se tem estendido nas partilhas Conexões: revista da Faculdade de Educação Física da UNICAMP, Campinas, v. 12, n. 3, p. 121-140, jul./set. 2014. 
digitais de conceitos e de preceitos. Na esteira do tema consumo e infância destacamos o texto "Mídia e Educação" de Assis. ${ }^{4}$ A autora faz alusão a quatro tipos de gerações: Analógica; X; Y e Google/Web 2.0.

Contextualizando cada geração de forma sucinta, podemos dizer que, segundo a autora ${ }^{4}$, a "geração analógica" nasceu e viveu um bom tempo sob a influência dos impressos, rádio, telefone fixo, cinema. A "geração X" (cuja letra indica uma incógnita) viveu sua infância e adolescência no Brasil pós regime militar, assim recebendo a influencia da televisão colonizada pelos "enlatados" americanos e japoneses. Contudo, cabe ressaltar que essa colonização deixou espaços para o consumo produtivo ${ }^{11}$ e que as relações não podem ser consideradas somente na sua linearidade. A "geração Y" é caracterizada pela sua bifurcação da geração precedente e da que se segue. É a primeira que vive em um mundo das redes e conexões com a internet sendo, muitos desses, pais e mães da chamada "geração Google/Web 2.0”. Essa última, considerada "multi-tarefa”, pois realiza várias tarefas ao mesmo tempo (fala ao celular enquanto interage no computador, televisão, etc.).

Os fluxos culturais entre essas gerações e dessas com as de outras nações se mostram distintas. Entretanto, nos interessa aqui os fluxos culturais da geração Google/Web 2.0, que demarca a geração contemporânea de uma infância líquida. ${ }^{8}$

Entre a discussão de uma cultura de fronteira, Santos ${ }^{15}$ considera que devido às identidades culturais não serem rígidas e nem imutáveis são, pois, identificações em curso. E por mais sólidas que pareçam "escondem negociações de sentido, jogos de polissemia, choques de temporalidades em constante processo de transformação". 15:31 Ainda segundo o autor, "a zona fronteiriça é uma zona híbrida, babélica, onde os contatos se pulverizam e se ordenam segundo micro-hierarquias pouco susceptíveis de globalização" ${ }^{14: 153}$ Ferraço ${ }^{16}$ contribui e alarga a discussão ao conferir que no estranhamento do movimento de viver entre fronteiras é a ambivalência estabelecida nos sistemas culturais que faz emergir o hibridismo.

Esses movimentos se dão em escalas macro e micro, se notarmos os contextos postos na atual geração. Por exemplo, a criança ao mesmo tempo em que formaliza práticas ${ }^{11}$ na fronteira dos espaços formais de educação também é enviesada pela fronteira global da Conexões: revista da Faculdade de Educação Física da UNICAMP, Campinas, v. 12, n. 3, p. 121-140, jul./set. 2014. ISSN: 1983-9030 
rede mundial de computadores (globalização da infância). Nas palavras de Sarmento, ${ }^{1}$ a constituição de um mercado de produtos culturais para a infância, de fato, contribui para sua globalização. Costa $^{8}$ indica que as crianças consomem os bens culturais distribuídos nos artefatos, por exemplo, as produções midiáticas. Nesse ponto, é que devemos nos deter para observar as construções (traduções) de uma tática da infância. Essas podem ser compreendidas na capacidade de que existe a reinterpretação ativa das crianças dos produtos culturais que é marcada numa base local, cruzada pelas culturas globalizadas, comunitárias e de pares. ${ }^{1}$

A cultura de fronteira marca a constituição da identificação da geração hodierna brasileira ao se constatar, como um dos indícios, que "um dado do Ibope/Net Ratings de junho de 2007 demonstra que mais de 3,4 milhões de brasileiros de 2 a 14 anos acessam a web de suas casas, mas estes representam apenas $19 \%$ de toda a população residencial online naquele ano". 4:124 Estamos convivendo com uma "geração virtual", que dispõe de identidades partilhadas, bens de consumo e produtos em comum. Entretanto, mesmo em meio à "virtualização" que engendra o contexto dessa nova geração ela ainda percorre no cotidiano os espaços produzidos para/por ela.

Nesse sentido, deveríamos observar quais os consumos produtivos ${ }^{11}$ caminham para a compreensão das autorias de infância no processo de construção de suas identidades. Por exemplo, a partir de uma dada brincadeira podemos perceber que os lugares no cotidiano se configuram em espaços de relações interpessoais, onde os caminhos de crianças se entrecruzam entre os pares e com os adultos também. Nesse instante, abre-se uma porta ao percebermos que "a cultura de pares permite às crianças apropriar, reinventar e produzir o mundo que as rodeia". 1:14 A relação com os pares - tanto quanto com a família, escola, comunidade, etc. - é desenvolvida pela interação da convivência, da realização de atividades e rotinas que permite a criança

exorcizar medos, representar fantasias e cenas do quotidiano, que assim funcionam como terapias para lidar com experiências negativas. Esta partilha de tempos, ações, representações e emoções é necessária para um mais perfeito entendimento do mundo e faz parte do processo de crescimento. $^{1: 14}$

Conexões: revista da Faculdade de Educação Física da UNICAMP, Campinas, v. 12, n. 3, p. 121-140, jul./set. 2014. 
Nesse contexto, os espaços de educação formal mostram-se como palcos das relações tecidas das redes de "saberesfazeres" dos praticantes, indicando pistas de que esses se configuram como locais importantes para observarmos as relações de pertencimento das crianças. Quanto a isso, Ferraço ${ }^{16}$ enfatiza sobre nossa responsabilidade com respeito aos processos curriculares realizados, e não de ir a escola julgar o que está sendo feito ali. Assim, emerge a importância do lugar, destaque que implica assumir o posicionamento a favor de um pertencimento a esse "espaçotempo".

\section{INFÂNCIA LÍQUIDA, CRIANÇAS TRADUZIDAS: (IMPLIC)AÇÕES PARA O PENSAR EDUCAÇÃO FÍSICA NA EDUCAÇÃO INFANTIL}

Coloca-nos alarmante considerar que "os traços identitários de cada região estão sendo transformados frequentemente". 10:6 Essa premissa corrobora o pensamento de que nossa prática pedagógica deve ser considerada mediante o interesse "[...] em desqualificar as falas que assumem os sujeitos praticantes a partir de identidades fixas, imutáveis, possíveis de serem classificadas em categorias e/ou estruturas prévias de análise". ${ }^{16: 6}$

Nesse sentido, é importante ressaltar a emergência de uma infância líquida ${ }^{8}$ que atravessa as seguintes questões:

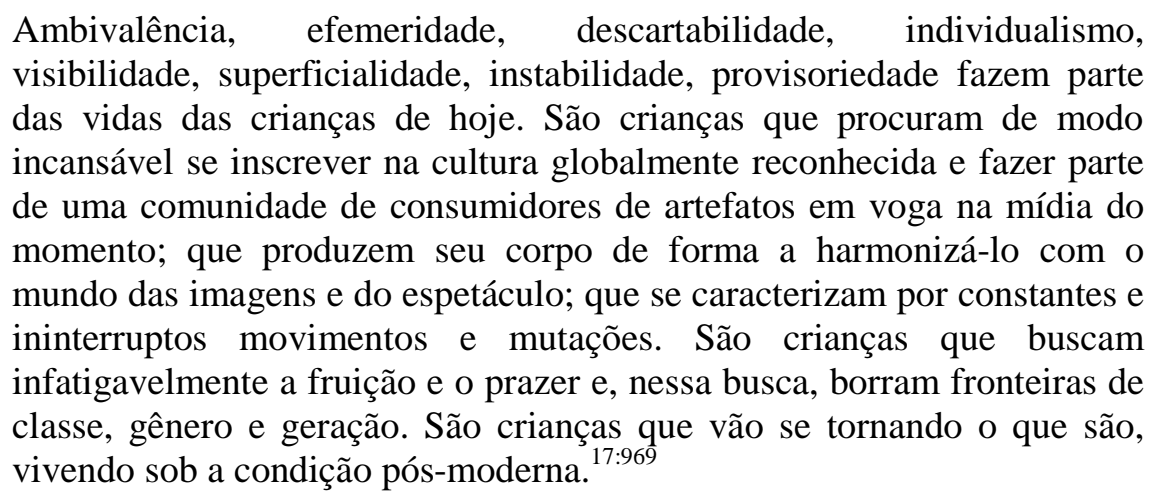
O consumo, enquanto eixo organizador da sociedade moderna líquida é um fenômeno que afeta a produção das identidades de infância. A partir da ótica da tradução, percebemos que o processo de configuração do sujeito híbrido indica percebê-lo em sua condição “[...] incalculável, semi-aquiescente, semi-opositor, jamais confiável, que produz um problema insolúvel de diferença cultural para a própria interpelação da autoridade". 16:5 Entretanto, 
isso não denota uma visão inferior desse sujeito, pelo contrário, indica uma qualidade potencial de confundir e ser inclassificável.

Destarte, compreendemos que a criança é inclassificável (ela é traduzida) devido sua característica híbrida: ela torna-se líquida. Compete a nós compreendê-la no âmago das construções operacionalizadas no cotidiano que repercutem os contornos identitários de sua geração. Uma geração não pode ser a justaposição de um corolário marginalizado pela cultura dominante; ela é o processo em curso, em suas bricolagens, ${ }^{11}$ é um vir a ser poético e livre de preconceitos proselitistas.

Essas questões são profícuas para se pensar a Educação Física na educação de crianças sob o viés dos conceitos de identidade, cultura, cotidiano e consumo. Traçar uma ótica fora do contexto social a qual os praticantes do cotidiano estão engendrados é (re)produzir um reducionismo das possibilidades. Nesse sentido, é necessário traçar um trabalho prévio de programação, planejamento e delimitação das metas e métodos de trabalhos a serem desenvolvidos. (Não apresentaremos métodos ou planos de trabalho aqui, pois, no enredo da discussão proposta, uma "receita" destoaria o processo de educação de crianças que exige criatividade, envolvimento e estudos específicos para cada contexto).

Em um dado estudo ${ }^{3}$, percebeu-se que na educação infantil a Educação Física é vista, muitas das vezes, como o "momento da brincadeira", do parque ou como o "momento do corpo". Indicando princípios para a superação desse desatino, Ayoub ${ }^{3}$ relata que, em primeiro lugar, existe a possibilidade da construção de relações de parceria que justificam a presença das "especialidades" dentro de um projeto em comum à educação de crianças. Outro pensamento remete a visão de criança como ponto de partida e que a expressão corporal caracteriza-se como uma das linguagens fundamentais para ser trabalhada. A criança é quase sinônimo de movimento, de brincadeira, pois através dessas particularidades é que vão se descobrir, descobrir o outro, o mundo a sua volta e as múltiplas linguagens. E como apontam Momo e Costa, ${ }^{17}$ as crianças conseguem metamorfosear seus corpos, desejos e condutas de acordo com as demandas do consumo. Entretanto, para além da aquisição de bens materiais ou serviços, o consumo também pode 
ser compreendido através da construção de significados e representações que constituem os processos de identificação.

Sob esse viés considera-se que a educação de crianças é uma educação para o saber-estarser no mundo. Há implicações quando se toma um espaço comum para educar crianças.

Parece que a escola, usualmente centrada em pedagogias da escrita e da oralidade, aos poucos se constitui como mais um lugar em que operam pedagogias visuais, ensinando sobre imagens desejáveis, sobre o que é in e o que é out nos modos de produzir o próprio corpo. Prestar atenção aos corpos das crianças pode fornecer elementos sobre como elas se estão tornando sujeitos e de como estão consumindo o mundo que aí está, e sendo consumidas por ele. ${ }^{17: 979}$

Essa atenção dada aos corpos das crianças pode muitas das vezes ocorrer no tempo-espaço da Educação Física. Extrapolando a consideração de Momo e Costa, ${ }^{17}$ consideramos que existem elementos minuciosos a serem considerados no cotidiano das instituições de educação de crianças. Por exemplo, em uma intervenção de Educação Física é proposto a um grupo de crianças uma atividade. Em certo momento é perguntado a uma das crianças o porquê dela não estar participando da atividade. Ela responde que é porque "não gosta daquela brincadeira". Ou seja, aqui existe um indício de que para as crianças muitas das atividades viram brincadeira. Nesse exemplo, podemos "linkar" a questão da tradução operada pelas crianças que ao se apropriarem da atividade a transformam em brincadeira atribuindo a ela novos sentidos e significados. A isso Certeau ${ }^{11}$ tem chamado de consumo produtivo; resta saber quais usos as crianças fazem dessas atividades. Parece-nos óbvio que elas não reproduzem da mesma forma, mas sim traduzem para novas formas de fazer com táticas de infância. As crianças recriam, mudam, transformam; deixam assim sua marca na brincadeira tanto quanto são por ela marcadas.

Alguns marcos interessantes, que ocorrem cotidianamente nas instituições onde se educam crianças, podem indicar indícios para a compreensão de como a presença da Educação Física corrobora a construção de uma identidade de infância. Um acontecimento pequeno pode nos remeter a uma grande reflexão. Por exemplo, quando uma criança diz que gostou de uma determinada brincadeira, mas não gostou da música (de um grupo de música infantil) - e que nesse caso preferia um samba. Esse exemplo mostra o indício do fluxo 
cultural $^{9}$ em que essa suposta criança participa. A relação entre o gosto musical (que perpassa relações de consumo) coexiste com a constituição da identidade.

Extrapolando o exemplo, na seleção de uma "simples" música para o trabalho pedagógico, fica claro e evidente de que existe um embate cultural na hora de se educar as crianças e, nesse sentido, é necessário que o professor saiba escolher e justificar suas ações. Sarmento aclara a discussão ao conferir que o espaço escolar se torna palco das trocas e disputas culturais e que "a multicuturalidade contemporânea não se faz sem a disputa das instâncias que procuram estabilizar princípios de justificação educacional"1:7. Acreditamos que não deva ser uma intenção "reformar" as crianças através das escolhas dos professores, mas sim de proporcionar uma abertura de leque para novas possibilidades - novas formas das crianças empreenderem um consumo produtivo dos produtos e serviços do mercado globalizado. Essas que vão além daquelas objetivadas, e ainda bem que assim o seja.

Outro exemplo que tem se tornado comum nas aulas de Educação Física é a construção de brinquedos populares realizado com as crianças ${ }^{5}$. Geralmente, essas atividades se conformam momentos singulares os quais nos fazem alçar algumas considerações acerca da constituição identitária dessas. Um fato curioso é quando, inicialmente, as crianças não conhecem os brinquedos ditos "populares".

Existem relações dos usos e apropriações ${ }^{11}$ dos brinquedos populares na construção das identidades das crianças. Ao construírem os brinquedos, elas atribuem sentidos e significados tanto ao sentimento de protagonismo quanto ao de pertencimento àquele contexto, como sendo o seu espaço de identificação. Muitas crianças expressam isso através do desejo de levar o brinquedo para casa. E mais, durante a brincadeira as crianças se apropriam do brinquedo, elegem formas de brincar, se ajudam entre si para que todos possam ter sucesso na brincadeira.

Essa questão indica que o fluxo cultural local das crianças sofre uma alteração via a influência de uma cultura adjetivada de "popular". Nesse instante, percebemos as contribuições possíveis para uma ação pedagógica, uma vez em que todos os praticantes participem ativamente em seu desenvolvimento - professor(a) de Educação Física, professor(a) regente de sala, crianças, direção pedagógica e administrativa. 
Outro fator que compreendemos ser profícuo nesse processo é identificar as traduções realizadas pelas crianças. Considerar a condição de "não ser" da criança implica em "confundir" uma versão colonizadora do processo educacional no momento que emerge as identidades híbridas de infância. Essa condição se traduz em um entre-lugar que demarca “[...] o que faz com que cada criança se insira na sociedade não como um ser estranho, mas como um actor social portador da novidade que é inerente à sua pertença à geração que dá continuidade e faz renascer o mundo". 1:2

Quando consideramos a existência de "crianças traduzidas", o fazemos, inicialmente, mediante os indícios que procuramos refletir a partir de nossa experiência pedagógica. Vale conferir que a criança está em um processo constante de transformação, ou melhor, de tradução permanente. ${ }^{9}$ Deixá-la protagonista nesse instante não significa a ausência do adulto - aqui especificamente o professor de Educação Física -, mas sim, sua presença justificada e respaldada em ações que contribuam, nesses termos, para uma educação "não colonizadora".

\section{CONSIDERAÇÕES FINAIS}

A discussão proposta neste ensaio colocou-se profícua mediante a interação teórica entre os autores e conceitos elegidos: cotidiano, cultura, identidade e consumo. A partir das reflexões produzidas percebeu-se que as crianças estão em constante processo de tradução mediante as relações estabelecidas no/com o cotidiano, sejam elas virtualmente e/ou materialmente. Neste ponto, as fronteiras de cultura aparecem nos contextos macro e micro indicando um fluxo cultural típico dessa geração marcada pela identidade de infância líquida.

O contato constante com outras culturas indica um processo de temporalidade que perpassa uma construção entre o passado (memória), o futuro (devir) e um presente onde ela "não é" nem um nem outro. Esse "não ser" não indica um "ser incapaz", mas uma condição poética em curso. A(s) criança(s) terá(ão) outra(s) identidade(s) que não a(s) pensada(s) inicialmente. Assim consideramos que a identidade não pode ser um marco traçado a priori. Essa condição mostra característica e pode indicar uma relação ambivalente na constituição das identidades de infância.

Conexões: revista da Faculdade de Educação Física da UNICAMP, Campinas, v. 12, n. 3, p. 121-140, jul./set. 2014. ISSN: 1983-9030 
Esses pontos indicam que a Educação Física tem um trabalho (ação) pedagógico a ser desenvolvido na educação de crianças. Ao considerarmos essas enquanto um grupo geracional marcado por suas características inerentes as conformidades sócio-históricas criadas para elas, tanto quanto, por elas, significa traçar inversões nos modelos escolarizantes colonizadores. De forma integrada e concomitante, através das experiências no/com o cotidiano, a abordamos na condição das possibilidades de tradução via inserção das crianças na/à cultura corporal mediante a potencialização de consumos produtivos.

\section{REFERÊNCIAS}

${ }^{1}$ SARMENTO, M. J. As culturas da infância nas encruzilhadas da $2^{\mathbf{a}}$ modernidade. Universidade do $2002 . \quad$ Dinho, em: $\langle$ http://cedic.iec.uminho.pt/Textos_de_Trabalho/textos/encruzilhadas.pdf $>$. Acesso em: 04 abr. 2012.

${ }^{2}$ SARMENTO, M. J. Gerações e alteridade: interrogações a partir da sociologia da infância. Educação \& Sociedade, Campinas, v. 26, n. 91, p. 361-378, maio/ago. 2005. Disponível em: 〈http://www.scielo.br/pdf/es/v26n91/a03v2691.pdf>. Acesso em: 12 abr. 2012 .

${ }^{3}$ AYOUB, E. Narrando experiências com a educação física na educação infantil. Revista Brasileira de Ciências do Esporte, Campinas, v. 26, n. 3, p. 143-158, maio 2005. Disponível em: <http://cbce.tempsite.ws/revista/index.php/RBCE/article/viewFile/165/174>. Acesso em: 12 abr. 2012.

${ }^{4}$ ASSIS, R. Mídia e educação. In: VIVARTA, V. (Coord.). Infância e consumo: estudos no campo da comunicação. Brasília: ANDI: Instituto Alana, 2009. p. 119-132. Disponível em: <http://serv01.informacao.andi.org.br/-101fb149_120c3b05921_-7ffd.pdf>. Acesso em: 12 abr. 2012. 
${ }^{5}$ OLIVEIRA, V. J. M.; MARTINS, D. G.; PIMENTEL, N. P. O cotidiano da educação infantil e a presença da educação física na poética de ser criança. Pensar a Prática, Goiânia, v. 16, n. 1, p. 118-133, jan/mar 2013. Disponível em: <http://www.revistas.ufg.br/index.php/fef/article/view/16188/13763 >. Acesso em: $10 \mathrm{abr}$. 2013.

${ }^{6}$ BAUMAN, Z. Modernidade e ambivalência. Rio de Janeiro: Jorge Zahar, 1999.

${ }^{7}$ BAUMAN, Z. Modernidade líquida. Rio de Janeiro: Jorge Zahar, 2001.

${ }^{8}$ COSTA, M. R. As configurações das infâncias na periferia urbana: crianças, educação e processos culturais. 2008. 221 f. Tese (Doutorado) - Faculdade de Educação, Universidade Federal do Rio Grande do Sul, Porto Alegre, 2008.

${ }^{9}$ HALL, S. A identidade cultural na pós-modernidade. 10. ed. Rio de Janeiro: DP\&A, 2005 .

${ }^{10}$ JESUS, R. C. Tradição e tradução: identidade, cultura e memória. In: ENCONTRO DE ESTUDOS MULTIDISCIPLINARES EM CULTURA, 6., 2010, Salvador. Anais... Salvador: $\quad$ Facom-UFBa, 2010. Disponível em: <http://www.cult.ufba.br/wordpress/24724.pdf $>$. Acesso em: 18 maio 2012.

${ }^{11}$ CERTEAU, M. A invenção do cotidiano: 1 . artes de fazer. 17. ed. Petrópolis: Vozes, 2011.

${ }^{12}$ BAUMAN, Z. 44 cartas do mundo líquido moderno. Rio de Janeiro: Jorge Zahar, 2013.

${ }^{13}$ GINZBURG, C. Sinais: raízes de um paradigma indiciário. In: ___. Mitos, emblemas, sinais: morfologia e história. São Paulo: Companhia das Letras, 1999, p. $143-$ 179.

Conexões: revista da Faculdade de Educação Física da UNICAMP, Campinas, v. 12, n. 3, p. 121-140, jul./set. 2014. ISSN: $1983-9030$ 
${ }^{14}$ SANTOS, B. S. Modernidade, identidade e a cultura de fronteira. In: Pela mão de Alice: o social e o político na pós-modernidade. 9. ed. São Paulo: Cortez, 2003. p. 135160.

${ }^{15}$ SANTOS, B. S. Modernidade, identidade e a cultura de fronteira. Tempo Social: revista de sociologia da USP, São Paulo, v. 5, n. 1/2, p. 31-52, 1993 Disponível em: $<$ http://www.fflch.usp.br/sociologia/temposocial/site/images/stories/edicoes/v0512/Moder nidade.pdf>. Acesso em: 09 abr. 2012.

${ }^{16}$ FERRAÇO, C. E. Currículo e pesquisa com o cotidiano: sobre usos, traduções, negociações e hibridismos da cultura como enunciação. In: AMORIN, A. C. R. (Org.). Passagens entre moderno para o pós-moderno: ênfases e aspectos metodológicos das pesquisas sobre currículo. Campinas: FE/UNICAMP, 2007. p. 3-7. Acesso em: $\langle$ http://www.fe.unicamp.br/gtcurriculoanped/documentos/Livro-Passagens-completo.pdf $>$. Acesso em: 23 maio 2012.

${ }^{17}$ MOMO, M.; COSTA, M. V. Crianças escolares do século XXI: para se pensar uma infância pós-moderna. Cadernos de Pesquisa, v. 40, n. 141, p. 965-991, set./dez. 2010. Disponível em: 〈http://www.scielo.br/pdf/cp/v40n141/v40n141a15.pdf >. Acesso em: 10 abr. 2013.

Recebido em: 28 abr. 2014 Aceito em: 25 ago. 2014 Contato: oliveira_vjm@ @otmail.com 